\title{
OS INSTRUMENTOS DE PLANEJAMENTO AMBIENTAL TERRITORIAL E SUAS APLICAÇÕES NO ÂMBITO MUNICIPAL: UMA ANÁLISE DO PLANO DIRETOR E EXERCÍCIOS DE ZONEAMENTO
}

\section{INSTRUMENTS OF ENVIRONMENTAL TERRITORIAL PLANNING AND THE SCOPE MUNICIPAL APPLICATIONS: AN ANALYZING OF THE MASTER PLAN AND THE ENVIRONMENTAL ZONING}

\author{
Antônia Vilaneide Lopes Costa de OLIVEIRA ${ }^{1}$ \\ Luiz Antonio CESTARO ${ }^{2}$
}

\begin{abstract}
Resumo: Este artigo apresenta o plano diretor e os zoneamentos de cunho ambiental como instrumentos de planejamento e gestão ambiental, levando em consideração a discussão acerca do planejamento ambiental territorial orientada por duas direções: as questões ambientais envolvidas no planejamento e a aplicação desses instrumentos no âmbito municipal. Para análise do planejamento voltado à totalidade do território municipal, consideraram-se os fragmentos deste, representado pelo campo e a cidade. Assim, o objetivo principal desse trabalho foi analisar a aplicação dos instrumentos de planejamento ambiental no âmbito dos municípios brasileiros. É possível perceber que o plano diretor, apresentado no Estatuto da Cidade e os exercícios de zoneamento direcionados ao planejamento ambiental são instrumentos que em seu bojo trazem as questões ambientais territoriais. No que concerne ao plano diretor, o primeiro desafio verificado é com relação ao recorte espacial que o plano deve abarcar, pois é necessária a elaboração de planos diretores que contemplem a totalidade do território. Já os zoneamentos de caráter ambiental são claramente voltados para o território total.
\end{abstract}

Palavras-chave: Plano diretor. Zoneamento ambiental. Zoneamento ecológico-econômico. Zoneamento geoambiental. Planejamento ambiental.

\begin{abstract}
This paper presents the master plan and geoenvironmental zoning natures as instruments of environmental planning and management. The discussion of territory environmental planning is guided by two directions: at first the environmental elements involved in planning and another is the implementation of these instruments at the municipal territory. So, to analyze the planning directed of the municipal territory we consider the fragments of its, represented by country and urban. Thus, the main objective of this study was analyzing the application of environmental planning instruments under the public management. The master plan inside of the Estatuto da Cidade (City Statute) and the geoenvironmental zoning aims to apply at the territorial environmental planning and it has focus in the environmental e territorial questions. Regarding of the master plan, the first challenge has been the specific spacial area that the plan can cover. It is necessary to prepare master plans that could include all the territory. The environmental zoning are directed for the territory totality.
\end{abstract}

\footnotetext{
${ }^{1}$ Doutoranda do Programa de Pós-Graduação e Pesquisa em Geografia/UFRN. Mestre em Desenvolvimento de Meio Ambiente/UFRN. E-mail: vilaneide_oliveira@yahoo.com.br

${ }^{2}$ Doutor em Ecologia e Recursos Naturais/UFSCAR. Professor do Departamento de Geografia da Universidade Federal do Rio Grande do Norte. E-mail: cestaro@cchla.ufrn.br
} 
Keywords: Master Plan. Environmental zoning. Ecological-economic zoning. Geoenvironmental zoning. Environmental planning.

\section{Introdução}

Foi com o advento da Revolução Industrial, no século XVIII, que a pressão sobre meio ambiente começou a se intensificar. Os recursos naturais foram tratados como matéria-prima de fonte inesgotável para gerar produtos e, consequentemente, acumulação de capital, fato que erroneamente foi tratado como progresso.

As sociedades foram deixando de ser agrícolas/rurais e se tornaram industriais/urbanas, causando o crescimento desenfreado das cidades, aumento do consumo de bens materiais, o uso desordenado dos espaços naturais, o aumento da produção de resíduos sólidos e outras tantas mazelas que afetam o ambiente natural, revelando um modelo de crescimento econômico degradador, que tem como principal causa a ausência de uma consciência ambiental de caráter sustentável.

Acerca disso, segundo o paradigma do desenvolvimento sustentável, as sociedades precisam utilizar os recursos provenientes da natureza de modo a não comprometer suas disposições para as gerações futuras (BELLEN, 2006). Assim, o desenvolvimento sustentável considera uma relação simbiótica entre os fatores econômicos, sociais, ambientais e culturais de uma sociedade, considerando o bem-estar social que concilie crescimento econômico, qualidade ambiental, justiça social e valorização cultural.

Pela falha na capacidade de provar sua aplicabilidade, o conceito de desenvolvimento sustentável é visto por muitos como uma falácia. De fato, esse modelo de desenvolvimento não tem conseguido alcançar simultaneamente todas as dimensões previstas e, na maioria das vezes, contempla mais a dimensão econômica. Entretanto, o importante realmente é não se deixar envolver por um total pessimismo e acreditar que uma mudança pode acontecer, apesar de não ser tão fabulosa.

Nesse sentido, surge o planejamento ambiental como ação de integração entre exploração de recursos naturais e sustentabilidade socioambiental. Santos (2004), afirma que "visando à sustentabilidade, o planejamento ambiental geralmente considera os critérios em longo prazo, mas busca estabelecer também medidas em curto e médio prazo". Assim, "o planejamento ambiental é visto como o estudo que visa à adequação do uso, controle e proteção ao ambiente, além do atendimento das aspirações sociais e governamentais expressas ou não em uma política ambiental" (SANTOS, 2004, p. 27).

No que concerne à elaboração do planejamento ambiental, deve-se ficar atento para a dimensão, em escala, desse planejamento. A maioria das discussões de cunho ambiental se realiza na escala mundial ou nacional, enquanto suas aplicações são feitas na dimensão local. A esfera de poder local responsável pelo planejamento do território é o poder municipal. Assim, cada município precisa estar atento para inserir a dimensão ambiental em seus instrumentos de planejamento e ordenamento do território.

Nesse sentido, a Constituição Federal do Brasil concede competência comum a União, aos Estados, ao Distrito Federal e aos Municípios para "proteger o meio ambiente e combater a poluição em qualquer de suas formas" (BRASIL, constituição da República Federativa do Brasil, art. 23, VI de 1988) e "preservar as florestas, a fauna e a flora" (BRASIL, constituição da República Federativa do Brasil, art. 23, VII de 1988). Nesse contexto, Machado (1996) afirma que qualquer dos entes públicos supracitados tem competência para aplicar a legislação ambiental, ainda que essa legislação não tenha sido de autoria do ente público que a aplica. 
Reconhecendo a necessidade de envolver as variáveis ambientais no planejamento municipal e de estabelecer uma política ambiental local, esta pesquisa buscou responder às questões: Como a dimensão ambiental está inserida nos instrumentos de planejamento e ordenamento do território? Como os fragmentos do território estão inseridos nos instrumentos de planejamento municipal brasileiro?

Assim, o objetivo principal desse trabalho foi analisar a aplicação dos instrumentos de planejamento ambiental no âmbito municipal. Para tanto, considerou-se necessário discutir as categorias campo e cidade consideradas fundamentais para a compreensão da relação entre planejamento ambiental e seus instrumentos no âmbito municipal; conhecer como a dimensão ambiental é abordada nos instrumentos de planejamento territorial municipal; conhecer como os fragmentos do território, representados pelo campo e a cidade, estão inseridos nos instrumentos de planejamento ambiental municipal brasileiro. Foram escolhidos para tal análise o plano diretor e os exercícios de zoneamento de cunho ambiental.

\section{O plano diretor e o zoneamento ambiental}

O ano de 1981 representou um marco na política ambiental brasileira, pois foi neste ano que se instituiu a Política Nacional de Meio Ambiente (PNMA), com o objetivo de "preservação, melhoria e recuperação da qualidade ambiental propícia à vida, visando assegurar, no País, condições ao desenvolvimento socioeconômico, aos interesses da segurança nacional e à proteção da dignidade da vida humana" (BRASIL, Lei n 6.938/1981, art. $2^{\circ}$ ).

Os instrumentos da PNMA são enfatizados no artigo $9^{\circ}$ da supracitada lei, destacandose o zoneamento ambiental, que apesar de estar presente desde 1981 na PNMA, foi regulamentado somente em 2002, através do Decreto $n^{\circ} 4.297 / 2002$, e a partir de então passou a ser chamado de zoneamento ecológico-econômico (ZEE).

O zoneamento ambiental também é apresentado no Estatuto da Cidade (Lei $\mathrm{n}^{\circ}$. 10.257/01). Essa lei regulamenta os artigos 182 e 183 da Constituição Federal e dispõe sobre a política urbana dos municípios. Como instrumentos de gestão ambiental, o Estatuto da Cidade apresenta o zoneamento ambiental (ZA) e o plano diretor (PD).

$\mathrm{O}$ zoneamento ambiental se constitui em um instrumento baseado na compartimentação do território em zonas ambientais relativamente homogêneas, que orientam o uso do solo segundo a capacidade de suporte do ambiente, portanto, define parcelas do território que podem ser utilizadas e parcelas que serão interditadas e/ou que terão seus usos manejados. Todavia, antes de uma abordagem mais detalhada acerca dos zoneamentos será necessário tratar do plano diretor.

O plano diretor se constitui em lei municipal e deve ser elaborado por cidades com mais de vinte mil habitantes.

O plano diretor é o conjunto de normas obrigatórias, elaborado por lei municipal específica, integrando o processo de planejamento municipal, que regula as atividades e empreendimentos do próprio Poder Público Municipal e das pessoas físicas ou jurídicas, de Direito Privado ou Público, a serem levados a efeito no território municipal. (MACHADO, 2005, p. 279).

O plano diretor se constitui em um dos principais instrumentos da gestão municipal. As diretrizes para sua elaboração são encontradas no III capítulo do Estatuto da Cidade. 
No art. 39, primeiro artigo do III capítulo do Estatuto da Cidade, é feita a primeira colocação concernente ao desenvolvimento sustentável, como pode ser observado a seguir:

Art. 39. A propriedade urbana cumpre sua função social quando atende às exigências fundamentais de ordenação da cidade expressas no plano diretor, assegurando o atendimento das necessidades dos cidadãos quanto à qualidade de vida, à justiça social e ao desenvolvimento das atividades econômicas, respeitadas as diretrizes previstas no art. $2^{\circ}$ desta Lei. (BRASIL. Estatuto da Cidade, cap.III, art. 39).

$\mathrm{O}$ art. $2^{\circ}$ do Estatuto da Cidade dispõe sobre parte das diretrizes gerais para elaboração do plano diretor. Nele estão dispostos alguns incisos que tratam diretamente de importantes questões ambientais relacionas a conservação e preservação, ao saneamento ambiental, ordenação e controle do uso do solo, poluição e degradação ambiental. Também nesse artigo está posta a responsabilidade do plano diretor em normatizar em consonância com o desenvolvimento sustentável, quando afirma que o plano diretor prevê a "garantia do direito a cidades sustentáveis, entendido como o direito à terra urbana, à moradia, ao saneamento ambiental, à infraestrutura urbana, ao transporte e aos serviços públicos, ao trabalho e ao lazer, para às presentes e futuras gerações" (BRASIL. Estatuto da Cidade, cap. I, art. $2^{\circ}$, I), e ainda a "adoção de padrões de produção e consumo de bens e serviços e de expansão urbana compatíveis com os limites da sustentabilidade ambiental, social e econômica do Município [...]" (BRASIL. Estatuto da Cidade, cap. I, art. $2^{\circ}$, VIII).

Ainda trazendo questões concernentes ao desenvolvimento das cidades, o Estatuto da Cidade coloca que o plano diretor é obrigatório para cidades "inseridas na área de influência de empreendimentos ou atividades com significativo impacto ambiental de âmbito regional ou nacional" (BRASIL. Estatuto da Cidade, cap. III, art. 41, V).

Carvalho e Braga (2001, p. 99), afirmam que o plano diretor é "também um instrumento de gestão ambiental urbana, talvez o principal deles, sobretudo pelo fato de não haver uma tradição de política ambiental em nível municipal no Brasil". Para apoiar essa afirmação estes autores mencionam o documento do Ministério do Meio Ambiente intitulado, "Cidades Sustentáveis: subsídio a elaboração da Agenda 21". Segundo os supracitados autores, esse documento estabelece quatro estratégias de sustentabilidade urbana, identificadas como prioritárias para o desenvolvimento sustentável das cidades brasileiras, e duas das quais remetem diretamente ao plano diretor:

1. aperfeiçoar a regulação do uso e da ocupação do solo urbano e promover o ordenamento do território, contribuindo para a melhoria das condições de vida da população, considerando a promoção da equidade, eficiência e qualidade ambiental; 2. promover o desenvolvimento institucional e o fortalecimento da capacidade de planejamento e gestão democrática da cidade, incorporando no processo a dimensão ambiental urbana e assegurando a efetiva participação da sociedade. (CARVALHO; BRAGA, 2001, s/p).

Nesse sentido, é certo que o plano diretor se constitui em instrumento da política ambiental dos municípios, pois segundo o Estatuto da Cidade, deve conter diretrizes que incorporam questões relacionadas às problemáticas ambientais. Entretanto, fica a cargo dos municípios a elaboração de um plano diretor que aborde as questões ambientais para a totalidade do município e ofereça soluções passíveis de operacionalização.

Carvalho e Braga (2001), afirmam que há um aspecto essencialmente intrínseco ao plano diretor que é a ordenação do uso e ocupação do solo urbano. Para tanto, os exercícios 
de zoneamento precisam estar articulados ao plano diretor, pois esses definem aptidões e restrições do município podendo orientar o ordenamento do território.

\section{Exercícios de zoneamento ambiental}

Desde o aparecimento do zoneamento ambiental na PNMA, este instrumento foi ganhando inúmeras contribuições em termos metodológicos, de aplicação e com relação ao seu direcionamento no processo de ordenamento do território. Assim, foram surgindo tipos diferenciados de zoneamento de cunho ambiental, entretanto, com a mesma proposição, definir uso do solo segundo a capacidade de suporte do ambiente.

O zoneamento ambiental apresentado na PNMA e no Estatuto da Cidade, surgiu como uma proposta orientada pelas questões ambientais para complementar os zoneamentos que já eram elaborados, pois "os zoneamentos agroecológicos, industriais e urbanos já faziam parte dos trabalhos desenvolvidos no Brasil com pretensões de melhor aproveitar os espaços pelas atividades econômicas" (LIMA, 2005, p. 38).

Apesar de estar presente na legislação ambiental brasileira, o zoneamento ambiental não possuía previsão jurídica específica, portanto, não estava definido legalmente, quanto a objetivos, metodologia e escala de aplicação. Essas definições ficaram a cargo de acadêmicos e planejadores, que deram um caráter técnico/científico a esse tipo de zoneamento. Para estes, o zoneamento ambiental considera a integração dos elementos físicos e bióticos.

Assim, para Santos (2004), esse tipo de zoneamento se justifica como um instrumento do planejamento ambiental na medida em que, compõe-se das fases de inventário e diagnóstico, que resultam na definição de áreas que compartimentam os diversos sistemas ambientais componentes do espaço estudado. Segundo Ross (2006, p. 149),

As preposições do zoneamento ambiental devem refletir a integração das disciplinas técnico-científicas na medida em que consideram as potencialidades do meio natural, adequando os programas de desenvolvimento e os meios institucionais a uma relação harmônica entre sociedade e natureza, cujo princípio básico é o ordenamento territorial calcado nos pressupostos do desenvolvimento com políticas conservacionistas.

Nesse sentido, o zoneamento ambiental se apresenta como um instrumento comprometido com as problemáticas ambientais, porém, de difícil operacionalização.

Contudo, mesmo não tendo uma base metodológica totalmente definida, o zoneamento ambiental foi de grande relevância, pois introduziu a variável ambiental no planejamento e ordenamento do território, dando direcionamento para aqueles que surgiram posteriormente.

Assim, em 2002 o zoneamento ambiental foi regulamentado passando a denominar-se zoneamento ecológico-econômico (ZEE), mas não perdeu seu viés ambiental. O Brasil conta hoje, com o zoneamento ecológico-econômico (ZEE), que apresenta uma base metodológica delineada e objetivos definidos.

Dos objetivos e princípios do ZEE, para efeitos dessa análise tem-se:

Art. $2^{\circ}$ - O ZEE, instrumento de organização do território a ser obrigatoriamente seguido na implantação de planos, obras e atividades públicas e privadas, estabelece medidas e padrões de proteção ambiental destinados a assegurar a qualidade ambiental, dos recursos hídricos e do solo e a conservação da biodiversidade, garantindo o desenvolvimento sustentável e a melhoria das condições de vida da população. 
Art. $3^{\circ}$ - O ZEE tem por objetivo geral organizar, de forma vinculada, as decisões dos agentes públicos e privados quanto a planos, programas, projetos e atividades que, direta ou indiretamente, utilizem recursos naturais, assegurando a plena manutenção do capital e dos serviços ambientais dos ecossistemas.

Parágrafo único. O ZEE, na distribuição espacial das atividades econômicas, levará em conta a importância ecológica, as limitações e as fragilidades dos ecossistemas, estabelecendo vedações, restrições e alternativas de exploração do território e determinando, quando for o caso, inclusive a relocalização de atividades incompatíveis com suas diretrizes gerais. (BRASIL, Decreto no 4.297/2002).

Nos objetivos e princípios do decreto regulamentador do ZEE, é claramente identificado que se trata de um instrumento totalmente voltado para o planejamento e ordenamento do território. Ainda se percebe que esse instrumento oferece para gestão uma análise total do território e que pode ser realizado pelo ente municipal, pois, o referido decreto menciona que o ZEE desempenhará funções diversas, segundo algumas escalas, entre elas a que abrange a escala local.

O ZEE em escala local, representada por escala de 1:100.000 e maiores, tem como função indicativos operacionais de gestão e ordenamento territorial, tais como, planos diretores municipais, planos de gestão ambiental e territorial locais, usos de áreas de preservação permanente [...] (BRASIL. art. $2^{\circ}, \S 1^{\circ}$, III).

Assim, o zoneamento realizado sobre os auspícios do governo municipal não pode ser reduzido a macrozoneamentos que não acuram das necessidades ambientais do território municipal. As prefeituras não podem se eximir dessa função, tendo a responsabilidade de elaborar zoneamentos mais específicos à questões ambientais e de planejamentos territoriais ambientais comprometidos com a realidade local.

Observando os supracitados objetivos gerais do decreto que regulamenta o zoneamento ambiental, é possível perceber claramente que o ZEE é um instrumento totalmente voltado para o planejamento e ordenamento territorial, orientado pelo viés ambiental.

Em busca de incorporar o desenvolvimento sustentável, “o ZEE dividirá o território em zonas, de acordo com as necessidades de proteção, conservação e recuperação dos recursos naturais e do desenvolvimento sustentável" (BRASIL. Decreto 4.297/2002, cap. III, art.11). instrumento:

Está previsto no processo de elaboração e implementação do ZEE que esse

I - buscará a sustentabilidade ecológica, econômica e social, com vistas a compatibilizar o crescimento econômico e a proteção dos recursos naturais, em favor das presentes e futuras gerações, em decorrência do reconhecimento de valor intrínseco à biodiversidade e a seus componentes. (BRASIL. Decreto 4.297/2002, art. $\left.4^{\circ}, \mathrm{I}\right)$.

Ainda é importante observar que o ZEE,

II - contará com ampla participação democrática, compartilhando suas ações e responsabilidades entre os diferentes níveis da administração pública e da sociedade civil; e

III - valorizará o conhecimento científico multidisciplinar. (BRASIL. Decreto 4.297/2002, art. $4^{\circ}$, II, III).

No processo de elaboração do ZEE três elementos chamam atenção, a saber: o comprometimento com o desenvolvimento sustentável, o comprometimento com a gestão 
participativa e a valorização do conhecimento cientifico multidisciplinar. O conjunto desses elementos compõe o tripé essencial de um instrumento eficientemente comprometido com as problemáticas ambientais do meio em atuação.

Para Silva e Santos (2004, p.230), o ZEE é o resultado das relações de interdependência entre os subsistemas físicos, bióticos e socioeconômicos. "Pesa, em seu conteúdo, o diagnóstico da estrutura e da dinâmica ambiental e econômica, bem como do patrimônio biológico e cultural do país".

Além disso, de acordo com o art. $9^{\circ}$ do decreto em análise, os executores do ZEE deverão "apresentar arranjos institucionais destinados a assegurar a inserção do ZEE em programa de gestão territorial, mediante a criação de comissão de coordenação estadual, com caráter deliberativo e participativo, e de coordenação técnica, com equipe multidisciplinar" (BRASIL. Decreto no 4.297/2002, art. 9, I).

Nesses moldes, o processo metodológico e o conjunto de procedimentos operacionais do ZEE dificultam sua elaboração em nível técnico-acadêmico, pois além da necessidade de se articular com os atores políticos, necessita de uma equipe composta por profissionais de diversas áreas. Logo, cede espaço para que os trabalhos de teses e dissertações escolham zoneamentos passíveis de realização por um pesquisador ou pequeno grupo destes, a exemplo do zoneamento geoambiental. Este último pode ser parte integrante do ZEE local ou um instrumento extra que auxilie no planejamento e ordenamento do território.

O zoneamento geoambiental se constitui em um tipo de zoneamento realizado no âmbito técnico/acadêmico. Esse zoneamento se diferencia do ZEE pelas variáveis enfatizadas em sua metodologia. Além do componente ambiental fortemente orientado para fins de preservação e conservação, o zoneamento geoambiental ainda aborda os usos da terra e consequentemente as pressões humanas causadas por tais usos.

O processo metodológico para a realização do zoneamento geoambiental consiste em compartimentar o território em unidades geoambientais analisadas a partir da integração dos elementos da paisagem, ou seja, os dados de geomorfologia, geologia, pedologia, clima, vegetação e da intervenção antrópica. Essa análise é calcada na teoria geossistêmica, portanto, não permite uma avaliação em partes separadas dos sistemas ambientais que compõe o território municipal. É importante destacar que a análise geossistêmica não considera a circunscrição do território, no entanto, esta deve ser considerada por se tratar da unidade onde se projeta o poder público local.

O zoneamento geoambiental se baseia nos estudos realizados através de levantamentos setoriais e/ou integrado dos recursos naturais e do meio ambiente, utilizando técnicas de sensoriamento remoto aéreo e orbital, além de geoprocessamento. Adotam-se procedimentos metodológicos capazes de conduzir à delimitação de unidades geoambientais, em consonância com proposições geossistêmicas, definindo o potencial e as limitações de uso dos recursos naturais, as condições ecodinâmicas e a vulnerabilidade, como também o uso compatível, visando à sustentabilidade ambiental (FUNCEME, 2011).

Nesse sentido, o zoneamento geoambiental se constitui na melhor opção para elaboração de zoneamento em nível cientifico/acadêmico, pois além de contribuir com gestão ambiental, ainda utiliza os conhecimentos teóricos produzido nas universidades, a fim de consolidar as descobertas de profissionais comprometidos em fazer ciência a favor da sociedade. Assim, o zoneamento geoambiental se afirma com o comprometimento da comunidade científica também com as questões socioambientais.

De acordo com o exposto, fica claro que uma das principais qualidades dos exercícios de zoneamento direcionado ao planejamento ambiental territorial, é a inserção da variável ambiental em seu processo de elaboração, direcionando as tomada de decisões na esfera ambiental dos municípios. 
Por outro lado, outra problemática dos instrumentos de planejamento ambiental municipal precisa ser analisada, esta, diz respeito à escala de aplicação desses instrumentos.

Desse modo, as discussões em âmbito local trazem à voga as relações que se processam entre campo/cidade e como a gestão pública, responsável pela esfera ambiental, percebe esses fragmentos do território. Assim, torna-se essencial conhecer como o território enquanto unidade político-administrativa trabalha o planejamento ambiental na perspectiva da ligação campo-cidade, enquanto totalidade do território.

\section{O campo e a cidade no planejamento ambiental municipal}

Os termos 'rural' e 'urbano' adquiriram inúmeras contribuições nos debates de suas definições. Logo, são encarados como fundamentais para o planejamento territorial em diversas escalas e para o desenvolvimento em suas múltiplas dimensões: política, econômica, cultural e ambiental (BIAZZO, 2008).

Além das interpretações dos referidos termos, ainda é comum o emprego dos termos 'campo' e 'cidade' como sinônimo de 'rural' e 'urbano'. Entretanto, é preciso refletir sobre algumas diferenciações desses termos, sendo indispensável entender o território municipal e consequentemente suas frações, que se revelam como campo e cidade.

Santos (1998, p. 15), afirma que "é o uso do território, e não o território em si mesmo, que faz dele o objeto de análise social, o território são as formas, mas o território usado são objetos e ações, sinônimo de espaço humano, espaço habitado". O referido autor afirma que esse uso do território realizado pelo emprego do trabalho, permite produzir espaços diferenciados por funções diferentes (SANTOS, 1979).

Nesse sentido, Steinberger (2006) conclui que, se produzir é produzir espaço, a divisão espacial do trabalho também pode definir as frações do espaço, tendo em vista que estas adquirem funções diversas. Assim, a referida autora considera que campo e cidade são frações do território usado por apresentarem funções diferenciadas. Já rural e urbano representam o conteúdo do campo e da cidade, respectivamente. Esses conteúdos dizem respeito a uma gama de relações culturais, socioeconômicas e espaciais entre formas e processos derivados originalmente da cidade e do campo (MONTE-MÓR, 2006).

$\mathrm{O}$ intuito é pensar em espaços de fronteiras delimitadas, mas não fragmentadas. São delimitações funcionais de cada fração do território que se integram e mantêm relações capazes de promover o desenvolvimento do município.

Assim, Steinberger (2006) conclui que, "não cabe mais falar em separação cidadecampo e sim em relação cidade-campo como fruto da divisão territorial do trabalho e em relação urbano-rural como fruto da divisão espacial do trabalho".

Com efeito, a aplicação dos instrumentos de planejamento ambiental municipal precisa estar amparada nessa ligação, sendo aplicada a uma configuração territorial (município) como um todo, ou seja, que o território seja visto como uma totalidade de frações inter-relacionadas (STEINBERGER; AMADO, 2004).

Uma importante contribuição retirada dessa reflexão é a de que a antiga forma de pensar o espaço rural como neutro em relação aos processos sociais precisa ser modificada, passando a considerar "as mudanças que se processam no rural principalmente no que se refere à função, ao conteúdo social, às relações e mediações com o ambiente externo" (CAMPOS; KRAHL, 2006, p. 87).

É preciso superar a visão de que rural é a população dispersa no território, centrada no setor agropecuário, para passar à reconstrução de rural tanto como objeto de 
análise como de política pública, ao definir a âmbito do rural como o território construído a partir do uso e da apropriação dos recursos naturais, onde se originam processos produtivos, culturais, sociais e políticos. (CAMPOS; KRAHL, 2006, p. 87).

Campos e Krahl (2006, p. 97), enfatizam também que "a paisagem rural, suas propriedades e atributos são características que garantem identidade ao meio e o valor conferido a essas características por essa sociedade pode ser chamada de ruralidade". As apropriações desses valores pelos indivíduos do campo pode ser um forte fator de contribuição para a gestão ambiental, pois alimenta o compromisso de cuidado com o ambiente, podendo ser utilizadas nas propostas de planejamento ambiental, configurando uma gestão participativa.

É importante ressaltar que os valores do espaço urbano são de mesma importância e que a perda de valorização ambiental que vem ocorrendo no espaço urbano também precisa ser resgatada para auxiliar na gestão ambiental. Assim, a ideia de territorialidade, entendida como "o conjunto de práticas e suas expressões materiais e simbólicas, capazes de garantir a apropriação e permanência de um dado território por um determinado agente social" (CAMPOS; KRAHL, 2006, p. 98), precisa estar presente para o fortalecimento da gestão ambiental municipal.

Também é necessário que as discussões da gestão ambiental dos municípios considerem a totalidade dos territórios, ou seja, os fragmentos do campo e da cidade, para a construção de instrumentos de planejamento ambiental e territorial capazes de promover o desenvolvimento municipal.

As atribuições constitucionais, inclusive as de competência comum, como proteger o meio ambiente, fomentar a produção agropecuária e organizar o abastecimento alimentar, cuidar da saúde e da assistência social não estão restritas à área urbana. Portanto, o município não pode deixar de contemplar a totalidade do seu território e de sua população para efeito de planejamento e gestão territorial e implementação de políticas públicas. (MIRANDA, 2009, p. 14).

Nesse sentido, o ponto em comum entre o plano diretor e os zoneamentos de cunho ambiental que merece realce para fins desta análise é o direcionamento acentuado a um determinado fragmento do território. O que ocorre, muitas vezes, é a elaboração do plano diretor apenas para o espaço urbano e a elaboração de zoneamentos apenas para o espaço rural, como ocorre em muitos zoneamentos ambientais municipais (STEINBERGER; AMADO, 2006).

A própria denominação da Lei $\mathrm{n}^{\circ}$ 10.257/2001, Estatuto da Cidade, a mesma que dispõe sobre o plano diretor, é direcionada a uma política urbana. Em suas diretrizes gerais, a lei menciona:

Art. $1^{\underline{o}} \mathrm{Na}$ execução da política urbana, de que tratam os arts. 182 e 183 da Constituição Federal, será aplicado o previsto nesta Lei.

Parágrafo único. Para todos os efeitos, esta Lei, denominada Estatuto da Cidade, estabelece normas de ordem pública e interesse social que regulam o uso da propriedade urbana em prol do bem coletivo, da segurança e do bem-estar dos cidadãos, bem como do equilíbrio ambiental (BRASIL, Estatuto da Cidade. Lei $\mathrm{n}^{\circ}$ 10. 257/2001).

No entanto, de maneira conflitante, o capítulo III do Estatuto da Cidade, que dispõe sobre o plano diretor, menciona que "este plano, aprovado por lei municipal, é o instrumento básico da política de desenvolvimento e expansão urbana" (BRASIL. art. 40, Lei ${ }^{\circ}$ 
10.257/2001). Prossegue colocando que "o plano diretor é parte integrante do processo de planejamento municipal [...], e que este, "deverá englobar o território do Município como um todo" (art. 40, $\S 2^{\circ}$ ).

Sendo a dimensão do território o município como um todo, e não simplesmente o perímetro urbano, seria necessário a elaboração do plano diretor para a totalidade do território municipal. Todavia, o que é obrigatório para os municípios, no que concerne ao planejamento e ordenamento do território, de acordo com o art. 30 da Constituição Federal - CF- 1988, é a atuação no solo urbano.

Diz o art. 30 da CF que: “compete aos municípios: (...) VIII - promover, no que couber, adequado ordenamento territorial, mediante planejamento e controle do uso, do parcelamento e da ocupação do solo urbano". A Constituição Federal estabeleceu, de forma obrigatória, as atividades descritas com referência à parte urbana dos Municípios. Dependendo da necessidade, e da possibilidade de sua receita, o Município fará o ordenamento territorial da parte rural. Não está impedido de fazê-lo, mas a tanto não está obrigado pela Lei Maior. (MACHADO, 1996, p. 278).

As diretrizes gerais para elaboração do plano diretor estão previstas no art. $2^{\circ}$ do Estatuto da Cidade. Nos incisos IV e VIII desse artigo, está colocada a necessidade de planejar o território municipal e trabalhar seu ordenamento considerando a influência do urbano em outros fragmentos e o compromisso com o desenvolvimento sustentável. Ainda aparece no inciso VII a necessidade de trabalhar a articulação das atividades entre os espaços urbanos e rurais com vistas ao desenvolvimento do município.

Como as atividades praticadas no solo definem seus usos, é possível inferir que o planejamento e ordenamento do território precisam considerar a articulação dos fragmentos territoriais, portanto devem ser voltados para o território como um todo, processo essencial para a integração e complementaridade voltada ao desenvolvimento.

Apesar de não aparecer explicitamente, é possível perceber no art. $2^{\circ}$ do Estatuto da Cidade que existe a preocupação com o planejamento do território municipal. No texto, fica clara a atenção que precisa ser dada aos problemas que não estão no espaço urbano, mas que são provenientes da urbanização, inclusive aqueles relacionados ao meio ambiente. Por essa razão, é possível inferir que o plano diretor precisa considerar o campo e a cidade no processo de planejamento e ordenamento do território municipal.

Nesse sentido, alguns autores tratam da necessidade de considerar o território como um todo, tanto o campo quanto a cidade, ao se pensar em planejamento e ordenamento do território dos municípios. Miranda (2009), atenta para as questões legais de atuação no campo, confirmando algumas responsabilidades ao Instituto Nacional de Colonização e Reforma Agrária (INCRA), enfatizando a importância do ente local no desenvolvimento municipal.

Alguns posicionamentos veem a interferência municipal em relação ao território rural como inadequada, ao considerarem que, tanto do ponto de vista fiscaltributário quanto em relação à regulação das atividades, o ente federativo responsável deve continuar a ser a União. Não há dúvida de que a competência sobre a questão agrária é da União (pelo art. 22, I, da Constituição Federal), mas é o município o ente com a melhor condição para planejar o desenvolvimento local sustentável, a partir da compreensão das interfaces entre as questões urbana, agrária e a questão regional. Nesse aspecto, vale ressaltar a fragilidade das estruturas fiscal tributária e de controle do uso e ocupação do solo para as áreas rurais sob gestão do Instituto Nacional de Colonização e Reforma Agrária (INCRA). (MIRANDA, 2009, p. 34). 
Segundo preceitua o texto constitucional relativo à repartição de competências dos entes federados, é fundamental explicitar acerca da competência municipal sobre o plano diretor, especialmente, no que concerne ao ordenamento do território municipal. Com isso, tem-se notória a importância de estratégias que possam vincular o estabelecido na lei com os planos de articulações preconizados pelo INCRA.

Outrossim, Rolnik (2003) esclarece que a estratégia é proveniente do plano diretor. Um plano diretor único que abrange a totalidade do município, incluindo área urbana e área rural. Também advoga nesse sentido, o Plano Diretor Participativo: guia para a elaboração pelos municípios e cidadãos, elaborado pelo Ministério das Cidades no ano de 2004.

Quanto ao plano diretor e o saneamento ambiental, o referido documento afirma que as estratégias e prerrogativas se estabeleçam "nas condições que maximizem a promoção e a melhoria das condições de vida tanto no meio urbano quanto no meio rural" (MC, 2004).

Em se tratando de Brasil, a integração dos espaços urbanos e rurais precisa ser observada, sobretudo, nos municípios economicamente agrícolas e naqueles com acelerada expansão urbana. A expansão do urbano muitas vezes ultrapassa os limites funcionais e territoriais do rural, enquanto que, em outros municípios o crescimento do agronegócio expande também as fronteiras agrícolas, deixando-as próximas ou dentro dos limites urbanos. Podem ocorrer também os dois fenômenos em um mesmo município. Esses fenômenos configuram novas relações cidade-campo que precisam ser fortemente considerada na elaboração dos instrumentos de planejamento ambiental territorial.

Quanto aos exercícios de zoneamento (Zoneamento ambiental, Zoneamento Ecológico-Econômico, Zoneamento Geoambiental e outros), entendidos como instrumentos de planejamento e ordenamento do território, precisam também ser orientados para a totalidade do município, tendo em vista sua importante função, que é definir zonas de aptidão ou restrição, ou seja, dividir o território em parcelas que podem ou não serem utilizadas, ou restringir o uso de algumas.

Pensando no fenômeno já mencionado, referente ao encontro entre as fronteiras urbanas e rurais, é possível inferir sobre inúmeros conflitos existentes nesses casos. Em uma análise geral, um dos principais problemas são os conflitos de uso e ocupação da terra, ocasionadas pela sobreposição de áreas funcionais, resultando em conversão do uso da terra e reforma na estrutura fundiária, a ocupação de áreas verdes relevantes a conservação, a ocupação urbana em áreas ricas em minérios, entre outros.

Outro conflito socioterritorial evidente em muitos municípios brasileiros ocorre nas áreas periurbanas. Muitas vezes, essas áreas são ocupadas indevidamente, não possuindo estruturas de escoamento de esgoto, deposição adequada do lixo e captação de água. Nesses exemplos, a gestão municipal pode atuar na ordenação do território através de planejamento. Para tanto, os zoneamentos se apresentam como instrumentos dessa ação, pois revelam as potencialidades locais de uso do solo que podem ser transformadas em oportunidade de obtenção de renda para os indivíduos ocupantes dessas áreas.

O documento intitulado Plano Diretor participativo: guia para a elaboração pelos municípios e cidadãos de 2004, exemplifica que o aproveitamento dessas áreas pode servir para introdução de novos padrões de produção agrícola intensiva, "com alto valor agregado e articulado com a política municipal de abastecimento, capazes de constituir alternativas de geração de emprego e renda para os moradores dos bairros periféricos".

Para o planejamento e ordenamento do território municipal, os exercícios de zoneamento ainda fornecem dados de parques industriais incipientes, áreas com risco de deslizamento e não favoráveis a moradia, áreas rurais afastadas com alto potencial de preservação, potencialidade agrícola do solo, a compatibilidade ou incompatibilidade de 
atividades presentes no solo ou moradia irregular, entre outros apontamentos seguramente necessários para a gestão socioambiental do município.

Dessa forma, é possível afirmar que o planejamento e ordenamento do território devem considerar o município como um todo. Apesar da delimitação da fronteira municipal não ser um critério válido na análise dos sistemas ambientais, ela é justificada por definir o poder local que deve atuar em cada circunscrição territorial. Por isso, o poder municipal deve abarcar as frações do território simultaneamente, observando as peculiaridades desses fragmentos que se manifestam no campo e na cidade.

\section{Considerações finais}

De acordo com o exposto, é evidente a importância do plano diretor e dos zoneamentos de cunho ambiental (zoneamento geoambiental, zoneamento ambiental ou zoneamento ecológico-econômico) no planejamento ambiental do território municipal.

No que concerne ao plano diretor, o primeiro desafio verificado é com relação ao recorte espacial que este abarca. O Estatuto da Cidade traz claramente as questões relacionadas ao espaço urbano, no entanto, o capítulo que trata do plano diretor deixa claro que sua elaboração deve ser voltada para o território municipal, portanto cidade e campo.

Com relação ao zoneamento ambiental, a tendência é acompanhar a escala prevista para o plano diretor, tendo em vista que sua elaboração normalmente é prevista no próprio plano em questão, podendo ser elaborado apenas para um fragmento do território.

Por isso, é preciso atentar para o ZEE local que abarca também as questões ambientais, pois este traz em previsão jurídica uma elaboração para a totalidade do território.

Também, pode-se elaborar para fins de totalidade do território, o zoneamento geoambiental, pois este, metodologicamente é orientado para abarcar todo o território municipal.

Com relação à variável ambiental, dentro dos instrumentos em questão, é possível perceber que o plano diretor e os exercícios de zoneamento direcionados ao planejamento ambiental são instrumentos que trazem as questões ambientais territoriais.

No que concerne ao plano diretor, a variável ambiental está explícita no Estatuto da Cidade. No entanto, são os municípios os verdadeiros responsáveis pela inclusão de ações estratégicas voltadas para as problemáticas ambientais no plano diretor municipal. Não sendo nesses moldes, o planejamento ambiental territorial não se fará de acordo com o que mais se prega na política ambiental municipal, o desenvolvimento sustentável, pois estará amparando apenas uma parte do todo que forma o território do município.

No caso do zoneamento ambiental, zoneamento ecológico-econômico e do zoneamento geoambiental a variável ambiental é a norteadora de suas propostas, sendo enfatizadas questões de preservação e conservação de áreas com relevante interesse ecológico através do ordenamento do território, oferecendo informações a respeito de potencialidades e restrições de uso quanto ao uso do solo, e, ainda, referentes às intervenções degradadoras do homem.

É importante ressaltar que os zoneamentos tanto antecedem o plano diretor, oferecendo conhecimentos ambientais oriundos de uma análise mais voltada ao meio natural, como também podem ser articulados a este. O zoneamento geoambiental se reveste das mesmas características dos outros zoneamentos direcionados ao planejamento ambiental, mas é escolhido pelos membros acadêmicos devido ao suporte teórico utilizado e pelas variáveis estudadas em sua metodologia, além dos procedimentos técnicos para sua elaboração. 


\section{Referências}

BRAGA, Roberto. Gestão ambiental no Estatuto da Cidade: alguns comentários. In. CARVALHO, Pompeu Figueiredo de.; BRAGA, Roberto (orgs.). Perspectivas de Gestão Ambiental em Cidades Médias. Rio Claro: LPM-UNESP, 2001.

BELLEN, Hans Michael van. Indicadores de sustentabilidade: Uma Análise Comparativa $2^{\mathrm{a}}$ ed. Rio de Janeiro: Editora FGV, 2006.

BIAZZO, Pedro Paulo. Campo e rural, cidade e urbano: distinções necessárias para uma perspectiva crítica em geografia agrária. $4^{\circ}$ Encontro Nacional de Grupos de Pesquisa ENGRUP, São Paulo, 2008. Disponível em: <http://w3.ufsm.br/gpet/engrup/ivengrup/pdf/biazzo_p_p.pdf>. Acesso em 22 de janeiro de 2011.

BRASIL. Constituição da República Federativa do Brasil. Congresso Nacional: Brasília, 1988. Disponível em: < http://www.planalto.gov.br/ccivil_03/constituicao/constituicao.htm>. Acesso em 05 de setembro de 2011.

BRASIL. Decreto Federal n. 4297 de 10 de julho de 2002. Disponível em: < http://www.planalto.gov.br/ccivil_03/decreto/2002/d4297.htm>. Acesso em: 28 de agosto de 2011.

BRASIL. Estatuto da Cidade: guia para implementação pelos municípios e cidadãos. 2 ed. Brasília: Câmara dos Deputados, Coordenação de Publicações, 2002.

BRASIL. Estatuto da Cidade. Lei 10.257 de 10 de julho de 2001. Disponível em: < http://www.planalto.gov.br/ccivil_03/leis/leis_2001/110257.htm>. Acesso em: 28 de agosto de 2011.

BRASIL. Política Nacional de Meio Ambiente. Lei 6.938 de 31 de agosto de 1981. Disponível em: <http://www.planalto.gov.br/ccivil_03/leis/16938.htm>. Acesso em: 02 de agosto de 2011.

CAMPOS, Neio; KRABL, Mara Flora Lottici. Territorialidade: elo entre o espaço rural e o espaço urbano. In: STEINBERGER, Marília. Território, ambiente e políticas públicas espaciais. Brasília: LGE Editora, 2006.

MACHADO, Paulo Afonso Leme. Direito ambiental brasileiro. 6 ${ }^{\text {a }}$ ed.: São Paulo-SP. Editora Malheiros, 1996.

MACHADO, Paulo Afonso Leme. Direito ambiental brasileiro. $13^{\text {a }}$ Ed. São Paulo-SP. Ed. Malheiros, 2005,

MINISTÉRIO DAS CIDADES. O plano diretor participativo: guia para a elaboração pelos municípios e cidadãos. Brasília, 2004.

MIRANDA, Lívia Isabel Bezerra de. Planejamento em áreas de transição rural-urbana: velhas novidades em novos territórios. Revista Brasileira de Estudos Urbanos e Regionais. v.11, 
n.1. Associação Nacional de Pós-Graduação e Pesquisa em Planejamento Urbano e Regional: A Associação, 2009.

MONTE-MÓR, Roberto Luís. A cidade e o urbano. In: BRANDÃO, Carlos Antonio Leite. As cidades da cidade. Editora UFMG: 2006.

ROLNIK, Raquel. Estatuto da cidade e conferência das cidades: instrumentos para uma política urbana democrático-participativa. Katálysis. v.6. n.2. Florianópolis/SC, 2003.

ROSS, Jurandyr Luciano Sanches. Ecogeografia do Brasil: subsídios para o Planejamento Ambiental. São Paulo: Oficina de textos, 2006.

SANTOS, Milton. Por uma geografia nova. São Paulo: Hucitec-Edusp, 1978.

Espaço e sociedade. Petrópolis: Vozes, 1979.

O retorno do território. In: SANTOS, Milton;. SOUZA, Maria Adélia A;. SILVEIRA, Maria Laura. (Orgs.) Território: globalização e fragmentação. São Paulo: Editora HUCITEC; Associação Nacional de Pós-Graduação e Pesquisa em Planejamento Urbano e Regional, 1998.

SANTOS, Milton; SOUZA, Maria Adélia A.; SILVEIRA, Maria Laura. (Orgs.) Território: globalização e fragmentação. São Paulo: Editora HUCITEC; Associação Nacional de PósGraduação e Pesquisa em Planejamento Urbano e Regional, 1998.

SANTOS, Rozely Ferreira dos. Planejamento ambiental: teoria e prática. São Paulo: Oficina de Textos, 2004

STEINBERGER, Marília; AMADO, Theodelina Moreira. O espaço urbano no Zoneamento Ecológico-Econômico: esboço metodológico. In: STEINBERGER, Marília. Território, ambiente e políticas públicas espaciais. Brasília: LGE Editora, 2006.

STEINBERGER, Marília. Território, ambiente e políticas públicas espaciais. Brasília: LGE Editora, 2006. 